Article

\title{
A New Phase Transition Heat Exchanger for Gas Water Heaters
}

\author{
Zhoutuo Tan, Yunjia Yao, Chengning Yao, Jiapei Yang, Yougang Ruan and Qiuwang Wang * \\ Key Laboratory of Thermo-Fluid Science and Engineering, Ministry of Education, School of Energy and \\ Power Engineering, Xi'an Jiaotong University, Xi'an 710049, China; 15529569297@126.com (Z.T.); \\ 13259466955@163.com (Y.Y.); ycn17@mails.tsinghua.edu.cn (C.Y.); yangjp17@mail.tsinghua.edu.cn (J.Y.); \\ ruanyougang@163.com (Y.R.) \\ * Correspondence: wangqw@mail.xjtu.edu.cn; Tel.: +86-29-8266-5539
}

Received: 4 May 2018; Accepted: 7 June 2018; Published: 13 June 2018

\begin{abstract}
Gas water heaters take a major part in the Chinese water heater market, while the existing water heater have either low efficiency because of the single utilization of energy or the high failure rate that is caused by low temperature corrosion. A new structure of heat exchanger in the gas water heater is proposed is this article, the heat transfer method of which is not only forced convection, but also phase change heat transfer, which provides a higher heat transfer coefficient in condition of the same heat exchange area, and consequently promote the efficiency of the heat exchanger. An experimental study is carried out to compare the difference between the new water heater and the existing one on efficiency, and result shows that the new water heater is $6 \%$ higher in efficiency. Besides, this kind of water heater has a gentle temperature change when a sudden decrease or increase of gas flow rate occurs. An economic analysis is produced in order to predict the economic efficiency of the new heat exchanger. As a result, the new heat exchanger of the water heater can significantly promote the heat transfer efficiency and decrease the failure rate, and it is more economic efficient than the existing one.
\end{abstract}

Keywords: efficient heat exchanger; gas water heater; phase transition heat transfer

\section{Introduction}

Water heater has taken a big amount in energy consumption in people's daily life. According to the U.S. Department of Energy's (DOE) 2010 Building Energy Data Book, residential water heating consumes $13.1 \%$ of the energy that is delivered to residential buildings [1]. Gas water heaters account for $36.19 \%$ of Chinese water heater market, with the electric water heaters, solar water heater, and air-source heat pump heaters taking $47.36 \%, 8 \%$, and $1 \%$, respectively [2]. Water heating accounts for $39 \%$ of total energy consumption and a gas water heater takes $91 \%$ of the gas consumption in a normal family in the Unites States of America (USA) [3]. Consequently, the efficiency of the water heater is required to be high enough to fulfill the goal of economy and environment protection.

The working principle of the core part of the existing gas water heater is shown in Figure 1a. It is a finned tube heat exchanger through which the high temperature gas flows through the fin side of the heat exchanger to heat the water inside of the heat exchange coiler. The major heat transfer method takes the limited space heat transfer in the oxygen-free copper heat exchanger, and the high temperature smoke flows through the shell gap and the radiation and convective heat transfer in the limited space that occurs in the pipeline. The velocity of flue gas is low and it is laminar flow. When the heat flux density is low, the heat cannot be utilized sufficiently enough, which will result in a waste of energy. The approximate efficiency of the existing heat exchanger of gas water heater is $66 \sim 74 \%$, which does not meet the requirement of energy conservation [4]. 
A great amount of work has been done to promote the efficiency of the water heater. Aguilar $C$ [5] gives a conclusion that to promote the thermal and combustion efficiencies of water heaters, time, temperature, and turbulence (3Ts) should be improved of thr water heater, Lowering the flue gases temperature by $25^{\circ} \mathrm{C}$ reduces fuel consumption by $1 \%$ and improves the thermal efficiency by the same percentage [6]. Galitsky C [7] analyzed the combustion process and found that decreasing the excess air by $15 \%$ enhances the heating efficiency by $1 \%$, and $\mathrm{Cx} \mathrm{Cm}$ [8] found that water heater efficiency could be promoted by $2.5 \%$ if the excess $\mathrm{O}_{2}$ level is decreased by $1 \%$. Hongbin Y I et al. [9] optimized the air inlet structure of the burner in order to improve the combustion situation, which provides a slight increase on efficiency of $1.06 \%$. S Tajwar et al. [10] changed the surface design of the flow channel and improved the turbulence of combustion gases. S Eiamsa-Ard et al. [11] enhanced the heat transfer in tube by adding a helical tape inserts and improved turbulence of the flow in tube, which has been widely used by water heater producers to promote the thermal efficiency. SJ Craig [12] found that directing flue gas by baffle could also bring high thermal and combustion efficiency. These methods can enhance the heat transfer process and slightly promote the efficiency of a gas water heater.

The main way to improve the efficiency of the gas water heater is to add an additional heat exchanger to grasp the heat of the exhausted flue gas and the latent heat of water vapor [13], which has been widely used by water heater producers like A.O. Smith and Ariston. This kind of heaters is called a condensing water heater, which consumes about 30\% less energy than a traditional heater [14]. The efficiency of the condensing water heater is $21.1 \sim 28.7 \%$ higher than that of a traditional one [15]. Although the addition of condensing heat exchangers at the flue gas outlet can further utilize a small amount of water vapor that is generated by flue gas combustion, low temperature corrosion often occurs on the finned tube and causes a reduction of the thermal efficiency of the heat exchangers [16-20].

Other attempts are tried by changing the whole structure and heat transfer method of water heaters. In the gas water heater that was disclosed in U.S. Patent Publication No. US2007/0133963 A1 [21], a closed vacuum chamber full of particles is used as a core heat transfer member. The heat transfer coiler for heating the water is buried in the heat conduction particles in the cavity. The heat of the high temperature gas passes through the wall of the closed cavity in the form of heat conduction, then heat is conducted into heat conduction particles, and then into the coiler. Phase transition heat transfer is another method transmitting high heat flux, which is gradually applied in water heaters recent years. In the electric water heater that was disclosed in Chinese patent CN201510250211 [22], the heat transfer coiler is buried in a closed vacuum cavity containing water. Water is vaporized by heating tube and cooled by heat transfer coiler. In patent CN201610352526 [23], an electric water heater that is based on vacuum phase-change principles is also disclosed, consisting of several independent heating modules. Each module works as a vaporization and condensation unit. It has the advantages of high heat transfer coefficient, fast heating speed, isolation of water and electricity, safety, and compactness.

The invention provides a highly efficient heat exchanger component for rapid heat production in view of the problem that the heat utilization of the gas water heater in the prior art is low and the heat production speed is slow. The main heat transfer method for the new heat exchanger is not only forced convection, but also phase transition (see Figure 1b), which has not been found in public reporting. 


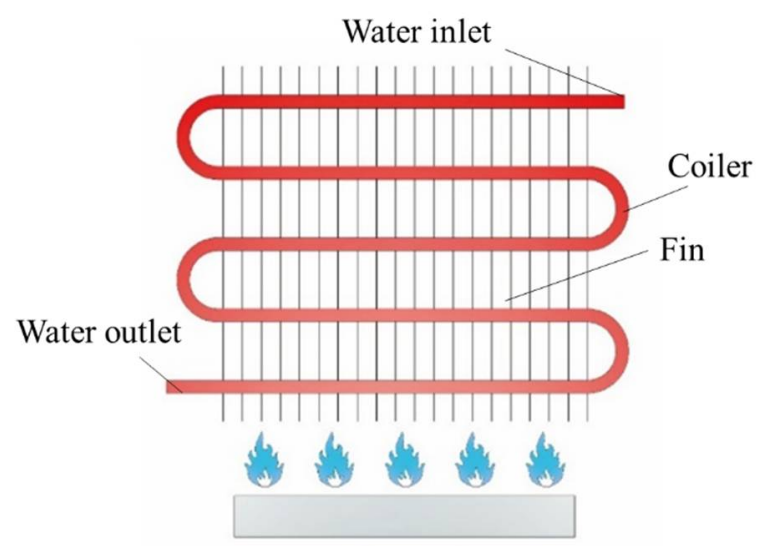

(a)

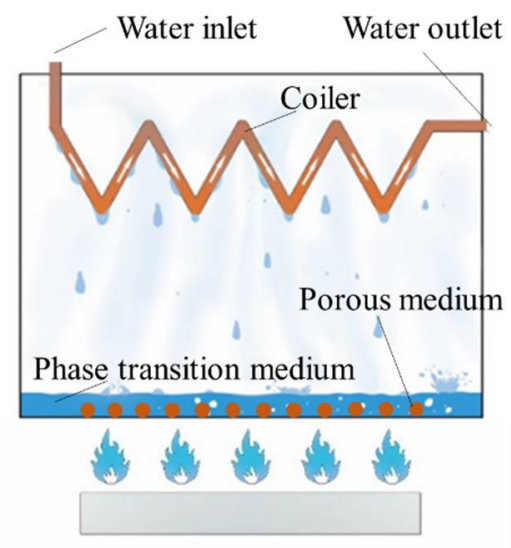

(b)

Figure 1. (a) Working principle of the existing heat exchanger in gas water heater; and, (b) Phase transition in the new heat exchanger in gas water heater.

\section{Materials and Methods}

Due to the high temperature of the flame, the finned tube cannot contact with the flame directly. The flue gas needs to be cooled before it rises up to the finned tube, which is made of copper in case that the heat exchanger gets burned and result in low heat flux. Phase transition heat transfer is an effective heat transfer method whose heat transfer coefficient is generally high and it is suitable for transferring high heat flux. By imitating heat pipe, a vacuum copper cavity is produced based on phase transition mechanism.

The new gas water heater consists of two heating parts, of which the inner part is a vacuum cavity. There is a coiler in the upper part of cavity. At down part of the cavity, below the coiler is phase transition medium, which is generally water or refrigerant. Porous medium is immersed in the liquid phase transition medium in order to increase the number of boiling core and accelerate the vaporization rate. The bottom of the cavity is the heating plate that is heated directly by high temperature flame. The external part of the heater is finned tube surrounding the cavity. The structure of the vacuum cavity is shown in Figure 2a and the experimental matter is shown in Figure $2 b$.

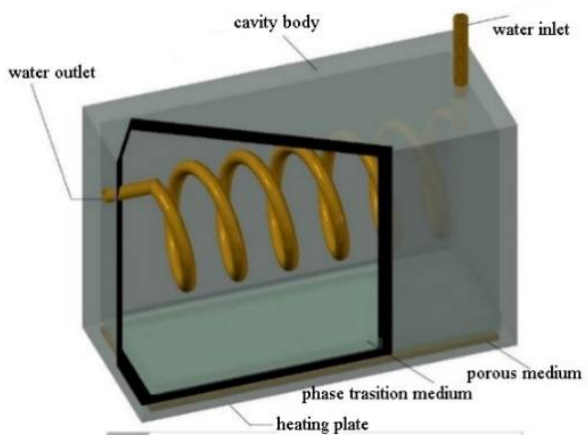

(a)

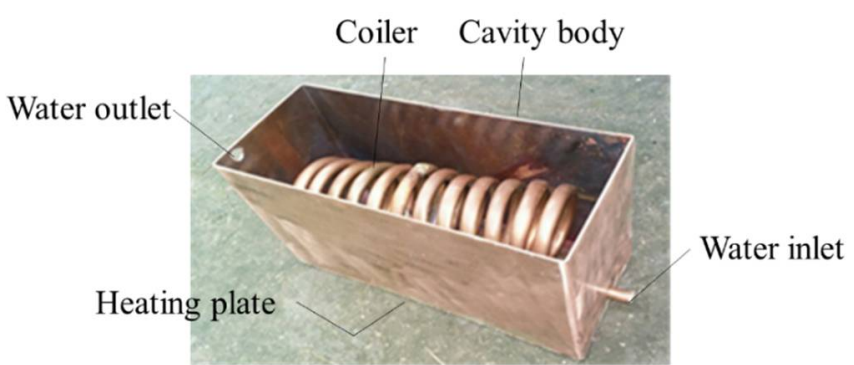

(b)

Figure 2. (a) Designed structure of the vacuum cavity; and, (b) Experimental structure of the vacuum cavity.

There is a shell that is made of steel outside the cavity in order to contain the cavity and locate the whole cavity above the burner. Between the cavity and the shell there is a flue gas passage where a second heat exchange pipe is arranged. After the bottom heat exchange plate of the body is heated by the heat source, the flue gas rises from the perimeter of the outside bottom of the inner cavity along the flue gas passage, and the heat is transferred to the heated fluid in the second heat exchange tube. 
The main structure of the heat exchanger is shown in Figure 3a and the experimental device is shown in Figure $3 b$. The geometrical parameter of the heater is shown in Table 1.

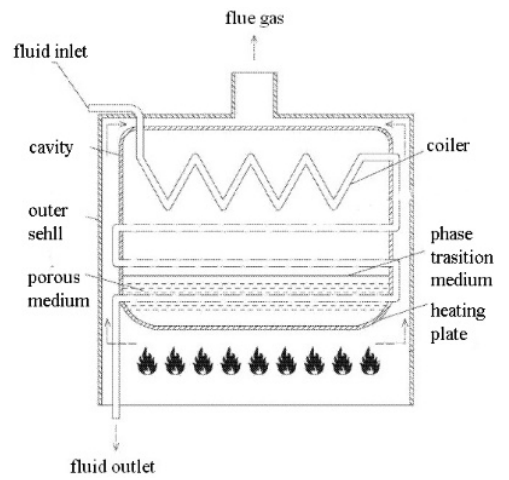

(a)

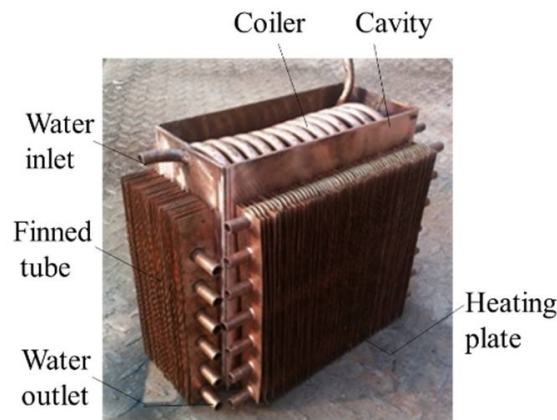

(b)

Figure 3. (a) Designed structure of the external part; and, (b) Experimental structure of the external part.

Table 1. Geometrical parameter of the heater.

\begin{tabular}{lccccc}
\hline $\begin{array}{l}\text { Geometry } \\
\text { Parameter }\end{array}$ & Value $\mathbf{( m m )}$ & $\begin{array}{l}\text { Geometry } \\
\text { Parameter }\end{array}$ & Value (mm) & $\begin{array}{c}\text { Geometry } \\
\text { Parameter }\end{array}$ & Value (mm) \\
\hline $\begin{array}{l}\text { Cavity Length } \\
\text { Cavity Width }\end{array}$ & 200 & Total Length & 240 & Diameter of pipe & 10 \\
Cavity Height & 250 & Total Width & 160 & Fin thickness & 0.5 \\
\hline
\end{tabular}

The working process of the heat exchanger is shown in Figure 4. After the gas water heater is started, the water in the inlet pipe enters the vacuum cavity and heated by the vapor phase transition medium, the medium condensed on the heat transfer pipe and drop back to the bottom of the cavity to be vaporized again. Then, water flow through finned pipes between the cavity and the outer shell to be heated again by the flue gas. In the main time, the flue gas was cooled by the heat exchange plate first, and then cooled by the finned tube, and finally flows out to the environment.

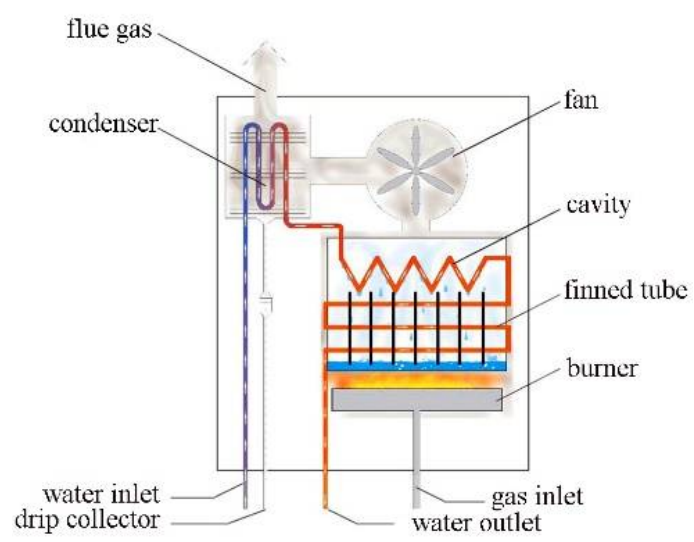

Figure 4. Working process of the new gas heat exchanger with addition of condenser.

Additional characteristics of the new heat exchanger have been found during analysis and experiment. When compared with the existing heat exchanger of gas water heater, the flue gas passage of the new heat exchanger is much narrower as a result of the vacuum cavity inside the body, which results in a higher velocity of the flue gas, and consequently brings a higher heat transfer coefficient, shown in Figure 5. Moreover, the new heat exchanger shows lower sensitivity on heat 
fluctuation. When changing the gas flow, the water temperature of the new heat exchanger will change much slower than the existing one.

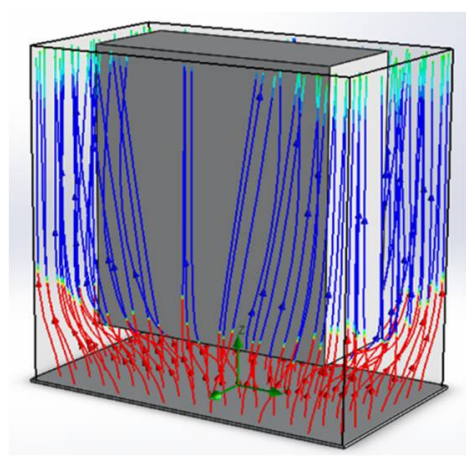

Figure 5. Velocity profile of the flue gas.

\section{Results and Analysis}

\subsection{Thermal Performance}

An experimental study has been carried out to test the behavior of the new heat exchanger and to compare the new heat exchanger with the existing one. Figure 6 shows the water temperature rise of the new heat exchanger when the gas flow is $0.01 \mathrm{~m}^{3} / \mathrm{min}$ and the water flow is $0.002 \mathrm{~m}^{3} / \mathrm{min}$, $0.003 \mathrm{~m}^{3} / \mathrm{min}, 0.004 \mathrm{~m}^{3} / \mathrm{min}$, and $0.005 \mathrm{~m}^{3} / \mathrm{min}$, respectively.

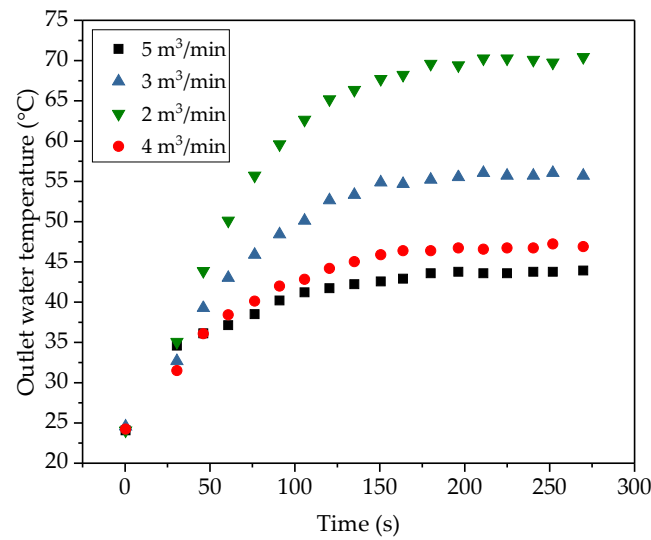

Figure 6. Outlet water temperature rise.

Figure 7 shows the comparison of the heat quantity absorbed by water between the new heat exchanger and the existing one when the gas low is $0.01 \mathrm{~m}^{3} / \mathrm{min}$ and water flow is $0.002 \mathrm{~m}^{3} / \mathrm{min}$, $0.003 \mathrm{~m}^{3} / \mathrm{min}, 0.004 \mathrm{~m}^{3} / \mathrm{min}$, and $0.005 \mathrm{~m}^{3} / \mathrm{min}$. Heat that is absorbed by water is calculated by:

$$
Q=\dot{m} c_{p}\left(T_{\text {out }}-T_{\text {in }}\right),
$$

where $\dot{m}$ is mass flow rate, $c_{p}$ is water heat capacity of water, and $T_{\text {out }}$ and $T_{\text {in }}$ is temperature of outlet water and inlet water, respectively. $\dot{m}$ can be calculated, as follows:

$$
\dot{m}=\rho \dot{V},
$$

$V$ is water flow and $\rho$ is water density. 
Different from the existing heat exchanger, the water flow has a significant effect on the efficiency of the new heat exchanger. It is found that the heat absorbed by water in the new heat exchanger is higher than the existing one and it increases from $6630 \mathrm{~W}$ to $7000 \mathrm{~W}$ with increase of the water flow, while the heat of the existing one fluctuates between $6340 \mathrm{~W}$ and $6550 \mathrm{~W}$. The thermal efficiency of the new heat exchanger is $94 \%$, while the existing one is $88 \%$ through converting. The heat that is absorbed by water in the new heat exchanger keeps increasing, but increases more and more slowly while water flow increases. Seemingly, there is a highest value of heat absorption foe the new heat exchanger and it depends on the water flow.

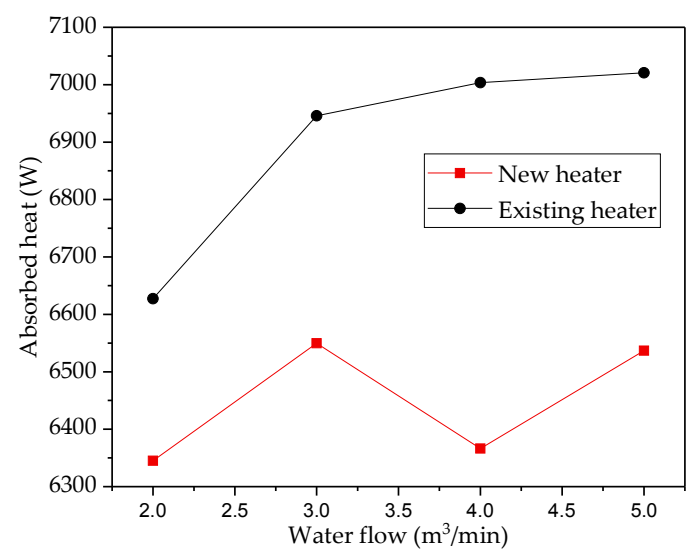

Figure 7. Absorbed heat of two heat exchangers.

The flue gas temperature of the two heat exchanger is investigated and is shown in Figure 8. The exhaust gas temperature of the new heat exchanger varies form $81^{\circ} \mathrm{C}$ to $76{ }^{\circ} \mathrm{C}$, while that of the existing one is from $97^{\circ} \mathrm{C}$ to $92^{\circ} \mathrm{C}$. It is found that exhaust gas temperature of the new heat exchanger is approximate $16{ }^{\circ} \mathrm{C}$ lower than existing one, and both of the exchangers' exhaust gas temperature decrease with the increase of water flow.

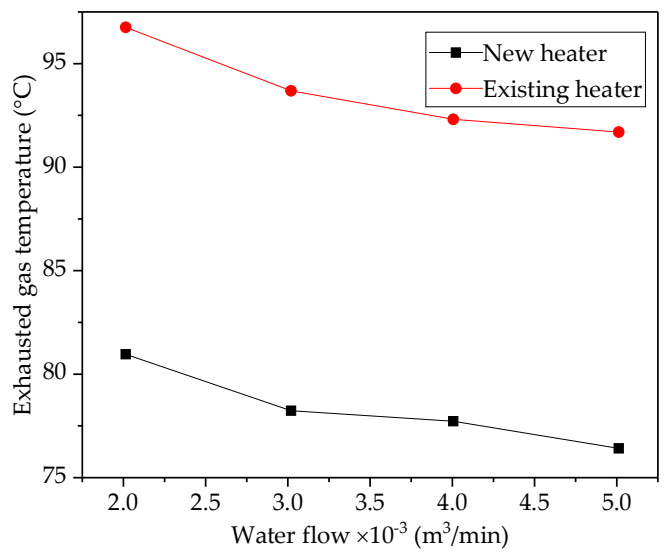

Figure 8. Exhausted flue gas temperature.

Additionally, an experiment testing the sensitivity about temperature change of the two heat exchangers. The flow of the gas will have a sudden change from $0.01 \mathrm{~m}^{3} / \mathrm{min}$ to $0.005 \mathrm{~m}^{3} / \mathrm{min}$, and there is a significant difference of water temperature change between the two heat exchangers (see in Figure 9). When gas flow decreased, the outlet water temperature of the existing heat exchanger goes down immediately and reaches steady condition in $20 \mathrm{~s}$, while the water temperature of the new one decreases slowly and stabilized in $70 \mathrm{~s}$. 


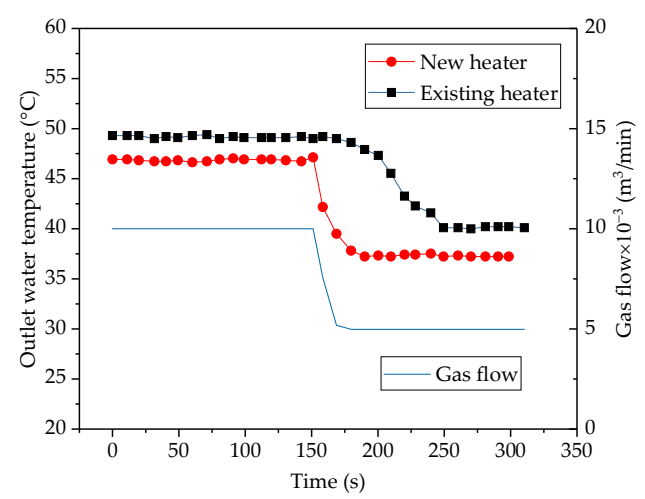

Figure 9. Water temperature change with fluctuation.

\subsection{Economic Analysis}

According to thermal performance of the new heater, a $6 \%$ promotion on thermal efficiency has been produced when compared to the existing heater. An economy analysis is proposed to obtain the economic efficiency of the new heater. For single user, the heat of water that is required per day can be calculated as:

$$
Q_{d}=c_{p} \rho V_{d} \Delta t
$$

where $c_{p}$ is heat capacity of water, $4.2 \mathrm{~kJ} /(\mathrm{kg} \cdot \mathrm{K}) . \rho$ is water density, $\mathrm{kg} / \mathrm{m}^{3} . V_{d}$ is volume of water, and $\mathrm{m}^{3} . \Delta t$ is temperature rise of water, ${ }^{\circ} \mathrm{C}$. Daily natural gas consumption can be calculated as:

$$
V_{g d}=\frac{Q_{d}}{q_{g} \eta}
$$

where $q_{g}$ is heat value of natural gas and $\mathrm{kJ} . \eta$ is thermal efficiency of gas water heater. The total operating cost of the heater can be calculated as:

$$
F_{d}=V_{g d} p_{g} n d
$$

where $p_{g}$ is price of natural gas, yuan $/ \mathrm{m}^{3} . n$ is number of heaters. $d$ is working days. For a single family water flow is $5.676 \times 10^{-3} \mathrm{~m}^{3} / \mathrm{min}$, temperature rise is $25^{\circ} \mathrm{C}$. Heat value of natural gas is $36,533 \mathrm{~kJ} / \mathrm{kg}$ and the price of natural gas is $2.8 \mathrm{Yuan} / \mathrm{m}^{3}$. Assuming that the gas water heater works one hour a day. The fixed cost of the heat exchanger of new heater is about 900 yuan, while the existing one is 720 yuan from gas heater producer Ariston. The total cost of the two heaters is shown in Figure 10 and it can be found that the cost would be equal when it is about 2.5 years.

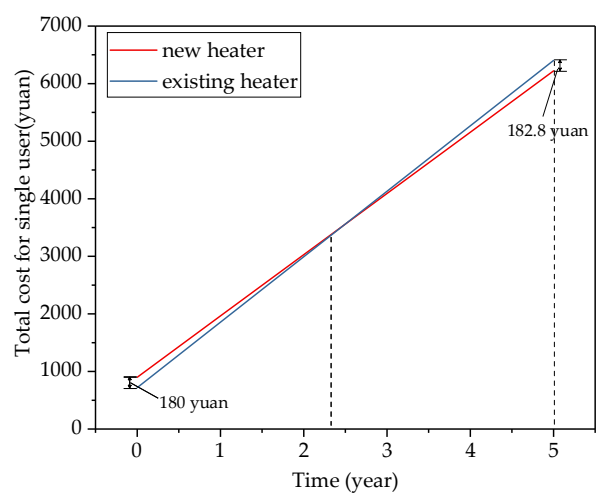

Figure 10. Total cost for single user. 
Taking China as example, there are 4.3 hundred million families and $36.19 \%$ of them use gas water heaters. It can be found that the new heater will conserve about $1.1 \times 10^{7} \mathrm{~m}^{3}$ of natural gas and save a cost about $3.1 \times 10^{7}$ yuan, as compared with the existing heater. Another character of the new heater that the avoidance of low temperature corrosion also contributes to the decrease cost of new heater, for a promising longer service life is obtained, which needs a further study.

\section{Discussion}

An experimental study is proposed to compare the behavior of the new heat exchanger and the existing one. It takes nearly $150 \mathrm{~s}$ for the new heater to reach steady condition, which is longer than that in the existing heater, because it takes time for phase transition medium to boil in the vacuum cavity every time that it starts. The finned tube around the cavity has the ability to heat water quickly and to make up for the long starting time.

The new heater has a better utilization of energy and it is more thermal-efficient than the existing one. Besides, the new heater has a best working condition and it will appear by keeping increasing the water flow and the most probable flow for best working condition is $0.01 \mathrm{~m}^{3} / \mathrm{min}$, because it is the design working condition for the experimental heat exchanger. The exhausted gas temperature of the new heater is lower than the existing one and higher than the dew point temperature of the combusted natural gas, which is approximately $50{ }^{\circ} \mathrm{C}$ [8]. Low temperature corrosion occurs when the temperature exhausted gas lower than its dew point temperature. The new heat exchanger efficiently reduces the exhausted gas temperature and avoids low temperature corrosion in the meantime.

With the boiling and condensing process of the phase transition medium, water temperature of the new heater decreases more slowly than that of the existing one, which is called low sensitivity of the new heat exchanger. Low sensitivity on heat source change is a good feature when it is used in a residential gas water heater because the gas flow is sometimes fluctuated in people's house and a low sensitivity of the fluctuation will bring a satisfying user experience.

With a promotion on thermal efficientcy $(6 \%)$, the new heater consumes less narual gas than the existing one. Although the fixed cost of the new heater is higher than the exisiting one (180 yuan), the fixed cost difference would be recovered in about 2.5 years. With a promising longer service time of the new heater, it would be further more economically efficient.

\section{Conclusions}

Gas water heaters are big natural gas consumer in residential buildings. The existing heater is either poor thermal efficiency or is likely to meet low temperature corrosion, which does not meet the requirement of energy conservation. Based on the problem, a phase transition heat exchanger is produced and an experimental study has been conducted comparing thermal behavior and using experience between the new heater and the existing one, and an economic analysis is produced to predict the economic efficiency. The work is shown, as follows:

(1) highly efficient heat exchanger component for rapid heat production is proposed in view of the problem that the heat utilization of the gas water heater in the existing heater is low and the heat production speed is slow, with the use of the phase transition medium.

(2) The heat transfer efficiency of the new heat exchanger in gas water heater is $6 \%$ higher than that of existing one through experiment.

(3) The exhausted gas temperature of the new heat exchanger $\left(81^{\circ} \mathrm{C} \sim 76^{\circ} \mathrm{C}\right)$ is higher than the dew point temperature of combusted natural gas $\left(60^{\circ} \mathrm{C}\right)$, which avoids the low temperature corrosion of heat exchanger.

(4) The new heater shows low sensitivity of heat source fluctuate and provides better using experience when there is a fluctuate of gas flow production, with the help of phase transition medium. 
(5) The new heater is more economic efficient and for individual user the cost can be recovered in about 2.5 years. For China, about $1.1 \times 10^{7} \mathrm{~m}^{3}$ of natural gas can be conserved with the use of the new heater.

(6) Avoidance of low temperature corrosion produces a longer service time of the new heater, and consequently contributes to a better economic efficiency, which remains to be further studied.

\section{Patents}

There are two patents resulting from the work reported in this manuscript, the number of which is WO/2017/166557 in PCT and CN201610204147 in Chinese patent, respectively.

Author Contributions: Z.T. and Y.Y. designed and performed the experiments, C.Y. and Y.R. did the calculation and designed the heat exchanger, J.Y. analyzed the data; Q.W. contributed materials and analysis tools, and provide the idea and structure of the paper.

Acknowledgments: The authors would like to thank the Foundation for Innovative Research Groups of the National Natural Science Foundation of China (No.51721004).

Conflicts of Interest: The authors declare no conflict of interest.

\section{References}

1. Hoeschele, M.; Springer, D.; German, A.; Staller, J.; Zhang, Y. Strategy Guideline: Proper Water Heater Selection; Office of Scientific \& Technical Information Technical Reports; U.S. Department of Energy: Washington, DC, USA, 2012.

2. Tian, Y.; Liu, R.; Yang, M.; Hao, Y.; Liu, Y. Market Survey and Analysis of Gas Water Heaters in Beijing. Gas Heat 2012, 32, B11-B13.

3. Lekov, A.B.; Franco, V.H.; Wong-Parodi, G.; McMahon, J.E.; Chan, P. Economics of residential gas furnaces and water heaters in US new construction market. Energy Effic. 2010, 3, 203-222. [CrossRef]

4. Yi, A.X.; Wang, Y.; Cheng, F.U.Z.; Pan, S.Y.; Guo, Q. Experimental Investigation and Saving Energy Analysis on High Efficiency Gas-fired Heater. Ind. Heat. 2002, 169, 50-52. (In Chinese)

5. Aguilar, C.; White, D.J.; Ryan, D.L. Domestic Water Heating and Water Heater Energy Consumption in Canada. CBEEDAC: Edmonton, AB, Canada, 2005; p. 359.

6. Department of Energy (DOE), Office of Industrial Technologies, Energy Efficiency and Renewable Energy. Best Practices Program; Information on Steam; Department of Energy (DOE), Office of Industrial Technologies, Energy Efficiency and Renewable Energy: Washington, DC, USA, 2001.

7. Galitsky, C.; Worrell, E. Energy Efficiency Improvement and Cost Saving Opportunities for the Vehicle Assembly Industry: An ENERGY STAR Guide for Energy and Plant Managers; Lawrence Berkeley National Laboratory: Berkeley, CA, USA, 2008; Volume 32.

8. Canadian Industry Program for Energy Conservation (CIPEC). Boilers and Heaters, Improving Energy Efficiency; Natural Resources Canada, Office of Energy Efficiency: Ottawa, ON, Canada, 2001.

9. Hongbin, Y.I.; Luo, C.; Liu, X.; Shang, Z.; Zou, C. Optimization of Partial Air Intake Structure of Burner in Blowing-type Gas Water Heater. Gas Heat 2014, 34, A28-A30.

10. Tajwar, S.; Saleemi, A.R.; Ramzan, N.; Naveed, S. Improving thermal and combustion efficiency of gas water heater. Appl. Therm. Eng. 2011, 31, 1305-1312. [CrossRef]

11. Eiamsa-Ard, S.; Promvonge, P. Enhancement of heat transfer in a tube with regularly-spaced helical tape swirl generators. Sol. Energy 2005, 78, 483-494. [CrossRef]

12. Craig, S.J.; Mcmahon, J.F. The effects of draft control on combustion. ISA Trans. 1996, 35, 345-349. [CrossRef]

13. Tan, S.; Luo, X.; Zheng, L. Research on condensing type gas water-heater. Nat. Gas Ind. 2002, $322,229$.

14. Federal Register Part VIII: Department of Energy, Office of Energy Efficiency and Renewable Energy. Available online: www.eere.energy.gov/buildings/appliance_standards/residential/pdfs/water_heater_ fr.pdf (accessed on 11 June 2018).

15. Grehier, A. Condensing Heat Exchanger for Heat Recovery from Flue Gases. In Proceedings of the International Symposium on Condensing Heat Exchangers, Columbus, OH, USA, 14 April 1987.

16. Pan, X.X.; Wei, D.S. Anti-corrosion of Condensing Gas Water Heater. Gas Heat 2005, 25, 11-14. 
17. Zhang, Y.; Huang, X.; Wang, F.; Xu, D. Corrosion Product Analysis and Corrosion Protection Measures on Heat Exchanger for Gas Water Heater. Gas Heat 2016, 36, A33-A37. (In Chinses)

18. Wenjuan, L.I. Causes and Improvement of Low Temperature Corrosion of Heat Exchanger in Condensing Gas Water Heater. Gas Heat 2016, 36, A27-A29. (In Chinese)

19. Hwang, K.; Song, C.H.; Saito, K.; Kawai, S. Experimental study on titanium heat exchanger used in a gas fired water heater for latent heat recovery. Appl. Therm. Eng. 2010, 30, 2730-2737. [CrossRef]

20. Zheng, Y.X.; Zhao, H.Y.; Ye, Y.Z.; Zhong, J.-S.; Xia, Z.-Z.; Wu, G.-F. Experimental Study on Corrosion Prevention of Low-temperature Section of Heat Exchanger in Condensing Gas Water Heater. Gas Heat 2007, 27, 35-41. (In Chinese)

21. Luo, C.-K. Heat Conducting Assembly for a Water Heater, and Method for Making the Heat Conducting Assembly. U.S. Patent 2007/0133963, 14 June 2007.

22. Wang, Q.; Su, B. Enclosed and Highly-Efficient Evaporation-Condensation Instant Water Heater. C.N. Patent 201510250211, 15 May 2015.

23. Wang, Q.; Wei, S. Quick-Heating Type Electric Water Heater Based on Vacuum Phase-Change Principle. C.N. Patent 201610204147, 24 May 2016.

(C) 2018 by the authors. Licensee MDPI, Basel, Switzerland. This article is an open access article distributed under the terms and conditions of the Creative Commons Attribution (CC BY) license (http:/ / creativecommons.org/licenses/by/4.0/). 